\title{
Complementary Standardless Quantitative Methods with EDS
}

\section{F Eggert ${ }^{1}$}

1. EDAX Inc., Ametek Materials Analysis Division, Mahwah, NJ, US.

Following Trincavelli at al. [1] the standardless EDS methods can be classified into five groups:

a) Measured net-count evaluation, procedures based on the application of first principle fundamental equations of microanalysis (with normalizing the results to $100 \%$ )

b) Net-counts evaluation methods based on same theory and which involve additionally a complex empirically measured databases or stored standards ('not normalized' optionally)

c) Algorithm based on Peak-to-background (P/B) ratios measurement (no inner normalization)

d) Special ratio-methods, e.g. with use of calibration factor curves (f-factor) or multiple measurements (variable take-off angle)

e) Methods developed based on Monte Carlo simulations (MC)

The special ratio-methods are often not applicable 'in general', but they are very useful for special application cases. The MC approach is much promising for the future, but it requires still much computer power and processing time than to be applicable for routine analysis or it is also limited for special applications with using MC supported precalculated curves.

The first group is basically a progression of the very first model developments for Electron Probe Microanalysis with a removal of the requirement to measure standards. The models are similar in properties, regardless of whether the classical ZAF notation or Phi-Rho-Z notation is used. As Newbury/Ritchie [2] have pointed out, there are several reasons the pure physics model calculation does not provide the accuracy. Therefore, currently those models are usually improved (adjusted) by utilization of a measured database ('remote standards').

The $\mathrm{P} / \mathrm{B}$ methods were developed after the introduction of EDS systems and were developed first mainly with the aim for particles and rough surfaces investigations. But the $\mathrm{P} / \mathrm{B}$ is also with benefits for 'in general' standardless spectra evaluation [3].

Therefore, only the methods (b) and (c) are currently reasonable to use for 'all purposes' standardless EDS analysis. Both approaches are complementary in application. It is known, the challenge with $\mathrm{P} / \mathrm{B}$ is to extract the proper $\mathrm{P} / \mathrm{B}$ values from measured spectrum. An accurate background determination is required to interpolate the values at peak energies [4]. Because the measured Bremsstrahlung statistics is much more influencing the $\mathrm{P} / \mathrm{B}$ values compared to net-counts, a higher number of X-ray are required to collect. Therefore, the determination of the 'measure signal' is usually the major error component of a $\mathrm{P} / \mathrm{B}$ based calculated quantitative result. This comes with worse base precision compared to net-counts evaluation models. But the disadvantage with required higher acquisition times was reduced much since the introduction of the method, due to the SDD detectors (developed last 2 decades) which accept more than 2 orders higher count rates compared to old $\mathrm{Si}(\mathrm{Li})$ detectors.

The general advantage of the $\mathrm{P} / \mathrm{B}$ based approach is that the relation 'concentration' vs. 'measurement effects' are nearly linear, because characteristic radiation and Bremsstrahlung have similar excitation and absorption effects. Less correction with interelement-effects means finally also 
less systematic uncertainties with the correction model. This is the reason that $\mathrm{P} / \mathrm{B}$ model is basically with much better base accuracy. The major uncertainties with net-count based approaches are systematic errors due to the correction model and due to the used parameters (e.g. MACs). But this is possible to improve in accuracy with including a good measured database finally.

Summarized, the errors are similar with practical short acquisition times but come from complete different major influences. So, both evaluations seem to be complementary and perhaps it makes sense to apply always both to double-check whether quantitative results can be really trusted.

References:

[1] J Trincavelli, S Limandri and R Bonetto, Spectrochimica Acta, Part B 101 (2014), p. 76.

[2] DE Newbury and NWM Ritchie, J. Mater. Sci. 50 (2015), p. 493.

[3] F Eggert, Microsc. Microanal. 24 (S1) (2018), p. 734.

[4] F Eggert, IOP Conf. Ser.: Mater. Sci. Eng 7 (2017), p. 012005.

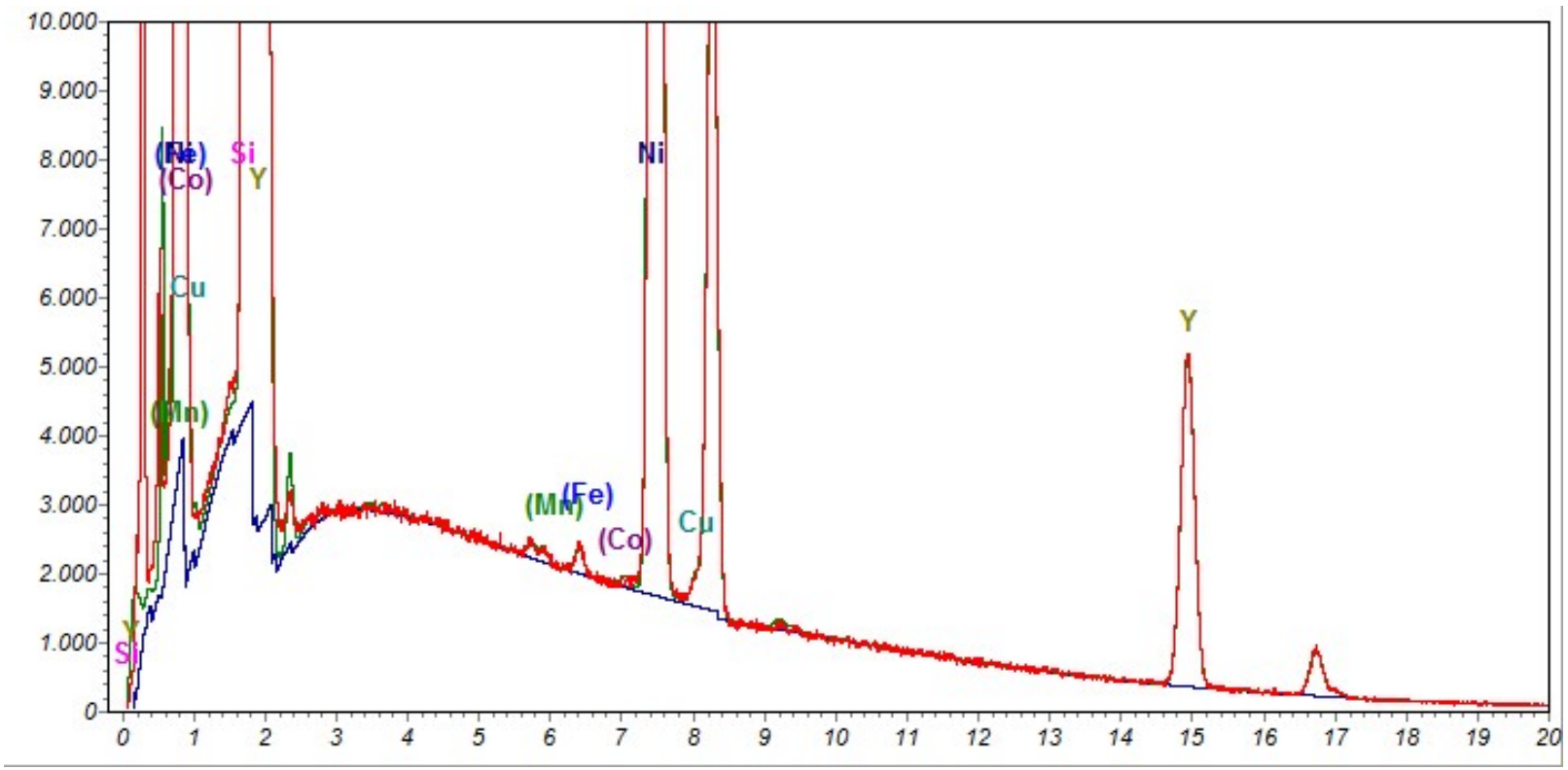

Figure 1. Spectrum from sample with major components of $\mathrm{Si}, \mathrm{Ni}, \mathrm{Y}$ ( $30 \mathrm{kV}$ excitation energy), 21 kcps OCR, 6 minutes acquisition time (expected concentrations Si 21.2\%, Ni 43.6\%, Y 35.2\%).

\begin{tabular}{|c|c|c|c|c|c|c|c|c|c|}
\hline & Symb & Line & $\mathrm{P} / \mathrm{B}$ & $\mathrm{C} 8$ & C-norme & Err\% & R & A & $\mathbf{F}$ \\
\hline 14 & $\mathrm{Si}$ & KS & 147.2 & 22.23 & 21.48 & 5.07 & 1.0076 & 1.0585 & 1.0102 \\
\hline 25 & Mn & $\mathrm{KS}$ & 0.7 & 0.06 & 0.06 & 37.39 & 1.0391 & 1.0097 & 1.2027 \\
\hline 26 & $\mathrm{Fe}$ & $\mathrm{KS}$ & 1.7 & 0.15 & 0.14 & 25.65 & 1.0412 & 1.0079 & 1. 2674 \\
\hline 27 & Co & $\mathrm{KS}$ & 0.2 & 0.02 & 0.02 & 86.44 & 1.0432 & 1.0065 & 1.1407 \\
\hline 28 & $\mathrm{Ni}$ & KS & 458.1 & 47.45 & 45.84 & 1.49 & 1.0452 & 1.0053 & 1.0647 \\
\hline 29 & $\mathrm{Cu}$ & $\mathrm{KS}$ & 2.4 & 0.27 & 0.26 & 12.52 & 1.0471 & 1.0044 & 1.0828 \\
\hline 39 & $\mathrm{Y}$ & LS & 169.0 & 33.33 & 32.20 & 3.08 & 1.0102 & 1. 0617 & 1.0027 \\
\hline \multicolumn{10}{|c|}{ PeBaZAF } \\
\hline $\mathbf{z}$ & Symb & Line & CPS & $\mathrm{CP}$ & C-norme & Erro & R & A & $\mathbf{F}$ \\
\hline 14 & $\mathrm{Si}$ & $\mathrm{Ka}$ & 3189.7 & 26.23 & 26.23 & 7.93 & 0.8246 & 0.2869 & 1.0103 \\
\hline 25 & Mn & $\mathrm{Ka}$ & 7.7 & 0.06 & 0.06 & 31.81 & 0.8722 & 0.8437 & 1.1773 \\
\hline 26 & $\mathrm{Fe}$ & $\mathrm{Ka}$ & 15.0 & 0.11 & 0.11 & 23.65 & 0.8762 & 0.8734 & 1.2326 \\
\hline 27 & Co & $\mathrm{Ka}$ & 1.1 & 0.01 & 0.01 & 65.53 & 0.8802 & 0.8970 & 1.1357 \\
\hline 28 & $\mathrm{Ni}$ & $\mathrm{Ka}$ & 3900.3 & 38.21 & 38.21 & 2.12 & 0.8843 & 0.9160 & 1.0719 \\
\hline 29 & $\mathrm{Cu}$ & $\mathrm{Ka}$ & 21.2 & 0.24 & 0.24 & 10.68 & 0.8884 & 0.9215 & 1.0921 \\
\hline 39 & $\mathrm{Y}$ & La & 1510.0 & 35.14 & 35.14 & 8.33 & 0.8291 & 0.2468 & 1.0024 \\
\hline \multicolumn{10}{|c|}{ eZAF } \\
\hline
\end{tabular}

Figure 2. First result list was determined with a $\mathrm{P} / \mathrm{B}$ based model. The absorption correction (A-factor column) is for Si and $\mathrm{Y}$ with only about $6 \%$. The $\mathrm{P} / \mathrm{B}$ determination uncertainty part is with about $1 \%$.

The second results are with Net-counts based model (no database was used). The absorption correction is for $\mathrm{Si}$ and $\mathrm{Y}$ with more than $70 \%$. This is more than 1 order of magnitude higher correction (also then with higher systematic uncertainties). The net-counts error part of total error $(\mathrm{Err} \%)$ is with $0.1-0.2 \%$ uncertainty only. 